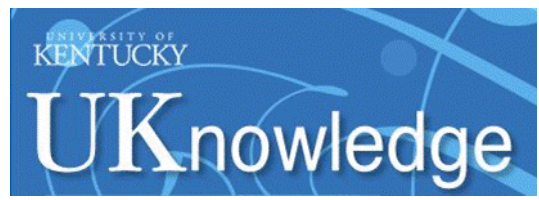

University of Kentucky

UKnowledge

$10-2020$

\title{
Evaluation of Bearing Voltage Reduction in Electric Machines by Using Insulated Shaft and Bearings
}

\author{
Peng Han \\ University of Kentucky, peng.han@uky.edu \\ Greg Heins \\ Regal Beloit Corporation, Australia \\ Dean Patterson \\ Regal Beloit Corporation, Australia \\ Mark Theile \\ Regal Beloit Corporation, Australia \\ Dan M. Ionel \\ University of Kentucky, dan.ionel@uky.edu
}

Follow this and additional works at: https://uknowledge.uky.edu/peik_facpub

Part of the Power and Energy Commons

Right click to open a feedback form in a new tab to let us know how this document benefits you.

\section{Repository Citation}

Han, Peng; Heins, Greg; Patterson, Dean; Theile, Mark; and Ionel, Dan M., "Evaluation of Bearing Voltage Reduction in Electric Machines by Using Insulated Shaft and Bearings" (2020). Power and Energy Institute of Kentucky Faculty Publications. 55.

https://uknowledge.uky.edu/peik_facpub/55

This Conference Proceeding is brought to you for free and open access by the Power and Energy Institute of Kentucky at UKnowledge. It has been accepted for inclusion in Power and Energy Institute of Kentucky Faculty Publications by an authorized administrator of UKnowledge. For more information, please contact UKnowledge@lsv.uky.edu. 


\title{
Evaluation of Bearing Voltage Reduction in Electric Machines by Using Insulated Shaft and Bearings
}

\author{
Digital Object Identifier (DOI) \\ https://doi.org/10.1109/ECCE44975.2020.9235474
}

\section{Notes/Citation Information}

Published in 2020 IEEE Energy Conversion Congress and Exposition (ECCE).

(C) 2020 IEEE Copyright Notice. "Personal use of this material is permitted. Permission from IEEE must be obtained for all other uses, in any current or future media, including reprinting/republishing this material for advertising or promotional purposes, creating new collective works, for resale or redistribution to servers or lists, or reuse of any copyrighted component of this work in other works."

The document available for download is the authors' manuscript accepted for publication. The final published version is copyrighted by IEEE and available as: P. Han, G. Heins, D. Patterson, M. Thiele, and D.M. lonel, "Evaluation of bearing voltage reduction in electric machines by using insulated shaft and bearings," 2020 IEEE Energy Conversion Congress and Exposition (ECCE), Detroit, MI, Oct. 11-15, 2020, pp. 5584-5589, doi: 10.1109/ECCE44975.2020.9235474. 


\title{
Evaluation of Bearing Voltage Reduction in Electric Machines by Using Insulated Shaft and Bearings
}

\author{
Peng Han, Member, IEEE, Greg Heins*, Member, IEEE, Dean Patterson*, Life Fellow, IEEE, \\ Mark Thiele* Member, IEEE, and Dan M. Ionel, Fellow, IEEE \\ SPARK Laboratory, ECE Dept., University of Kentucky, Lexington, KY, USA \\ * Regal Beloit Corporation, Australia, Rowville, VIC 3178, Australia \\ peng.han@uky.edu, greg.heins@ regalbeloit.com, dean.patterson@ regalbeloit.com, \\ mark.thiele@regalbeloit.com,dan.ionel@ieee.org
}

\begin{abstract}
Bearing voltages and corresponding currents in electric machines driven by pulse width modulation (PWM) converters with fast switching and high $d v / d t$ can cause premature bearing failures. This paper evaluates the bearing voltage reduction by using insulated shafts and bearings. An equivalent circuit representation of electric machines taking into account high-frequency effects is developed to show the production mechanism of bearing voltage, based on which simulations are performed with detailed finite element models for transient and simplified equivalent circuit for steady-state analysis. The steady-state equivalent circuit is then calibrated, by combined numerical calculations and experimental measurements, and used to predict the bearing voltage for various scenarios, proving the effectiveness of using insulated shaft and bearings in reducing the steady-state bearing voltage.
\end{abstract}

Index Terms-Bearing current, bearing voltage, capacitance, electric machine, insulated bearing, insulated shaft, PWM converter.

\section{INTRODUCTION}

Bearing failures in electric machines and electric machinedriven equipment are attributed to mechanical/thermal causes or bearing currents. Shaft voltages and the resulting bearing currents in line-operated electric machines are mainly produced by the homopolar flux, magnetic asymmetry and electrostatic effect. During the past decades, with the proliferation of variable speed drives using pulse width modulation (PWM) voltage source inverters, a growing number of bearing current induced premature bearing failures have been reported, calling for more research effort into bearing currents and the associated mitigation techniques [1].

All rotating machines potentially have bearing current issues, either of large or small horsepowers [2]. It has been shown that small inverter-fed ac machines are likely to suffer from electrical discharge machining (EDM) bearing currents, and larger machines are likely to be exposed to high-frequency circulating bearing currents [3].

The voltage across the bearing lubricant film, i.e., the bearing voltage $V_{b}$, can be built up by the electrostatic charge accumulation, the common mode voltage (CMV) through capacitve coupling, and the common mode current or magnetic asymmetry through inductive coupling. The bearing current will flow and damage the surface of bearing raceways once the instantaneous bearing voltage exceeds a given threshold value [2].

Main bearing current types include: the localized current induced by homopolar fringing magnetic fluxes, the leakage current to the ground, the non-circulating type caused by the shaft-to-frame voltage and the circulating type introduced by the shaft end-to-end voltage [4]. The bearing voltage is typically used as an indicator of bearing failures since both the non-circulating and circulating bearing currents are closely related to the potential drop across the bearing [5], [6]. The accurate prediction of bearing voltage and cost-effective mitigation solutions are important topics in this research area, such as the recent work [7], [8].

\section{Equivalent Circuit Representation of Electric MACHINES FOR BEARING VOLTAGE STUdY}

This paper takes a 3-phase 12-slot 10-pole permanentmagnet synchronous machine (PMSM) as an example study for the bearing voltage and evaluates its reduction potential by employing insulated shaft and bearings based on calibrated models, attempting to develop an effective and efficient modeling approach for bearing voltage and current study. By "insulated shaft", the author refers to the shaft whose diameter is reduced to fit in an insulation layer, e.g., plastic, between the shaft and inner ring of the bearing. "Insulated bearing" refers to the bearing whose outer surface of the outer ring and/or inner surface of the inner ring is E-coated or covered by plastic.

The equivalent circuit representation of the PMSM under study is developed for bearing voltage simulation, considering both the low-frequency and high-frequency behaviors, as illustrated in Fig. 1. The bearing voltage waveform shown in Fig. 1 depends heavily on the inverter output, cable impedance, ground impedance, high-frequency parameters of the machine and bearing parameters.

In order to show the effect of distributed parameters in transient simulations, the equivalent circuit includes details on winding turns. The construction of the 12s10p PMSM illustrated in Fig. 2 has an outer rotor with surface-mounted bonded ferrite magnets and an inner stator with 12 concentrated tooth wound coils, as shown in Fig. 3. 


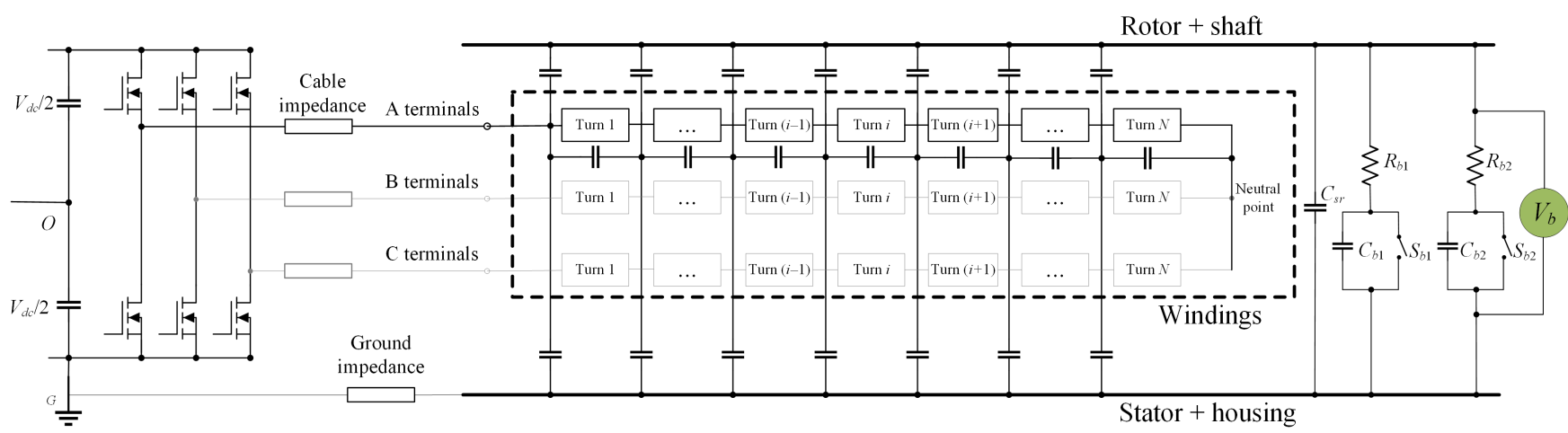

Fig. 1. Equivalent circuit for the PMSM under test taking into account both the low-frequency behavior and high-frequency effects. Windings are represented turn by turn and each winding turn block includes a resistance, an inductance and a back electromotive force (EMF). Only capacitances related to Phase A coils are shown for clear illustration.

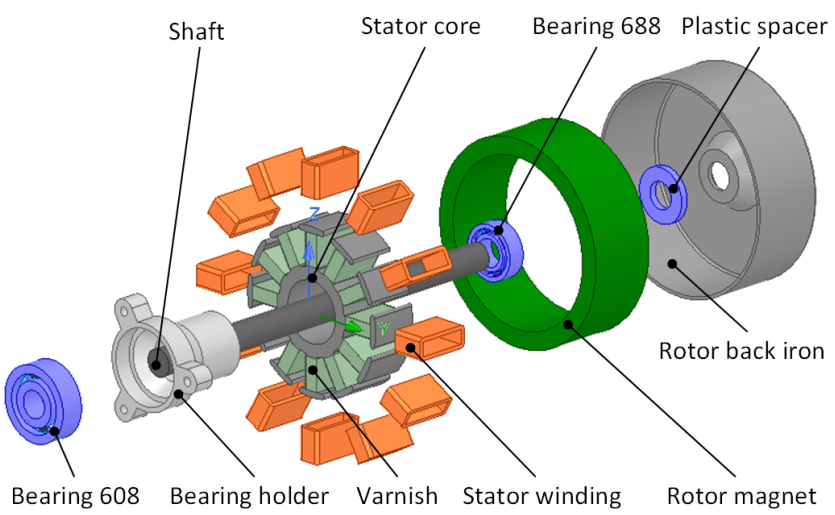

Fig. 2. Exploded view of a PMSM with an outer rotor.

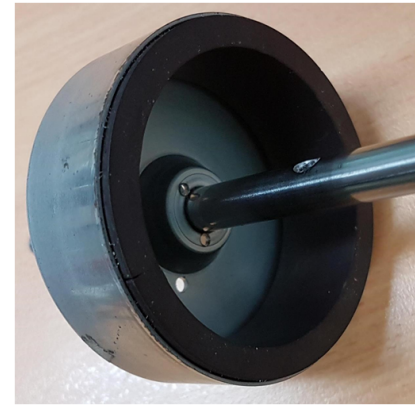

(a)

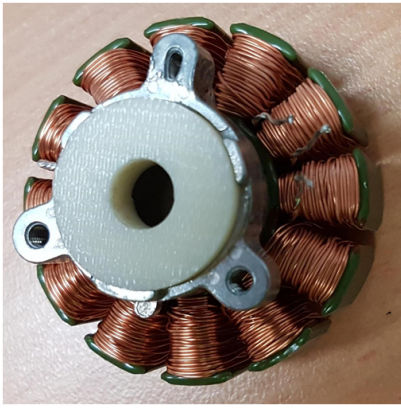

(b)
Fig. 3. PMSM under test: (a) outer rotor, (b) inner stator.

There are 39 turns in each coil and two $0.352 \mathrm{~mm}$ magnet wires in hand per turn. Both full ceramic bearings and steel ball bearings are used in the test for model calibration. Photos of the full ceramic bearing 608 and steel ball bearing 608 are included in Fig. 4.

In electric machines, the low-frequency behavior involves resistances and inductances at the fundamental frequency, which are commonly used for motor operation simulation and control purpose. The bearing voltage shown in Fig. 1, by contrast, is mainly induced by distributed capacitances and closely related to high-frequency inductances, resistances and parasitic capacitances of windings. These hig-frequency parameters need to be calculated and measured in ways

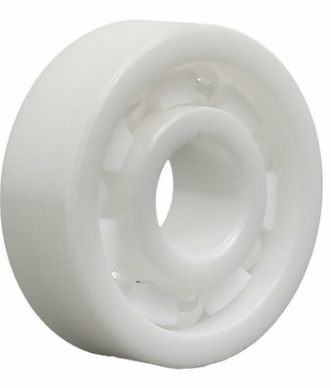

(a)

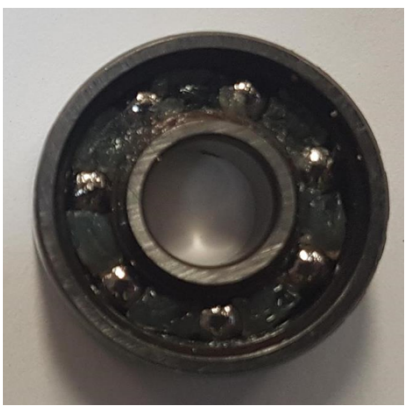

(b)
Fig. 4. Full ceramic bearing (a) and steel ball bearing (b).

different from those for resistances and inductances at the fundamental frequency.

\section{BeARing Voltage Simulation}

\section{A. Problem Formulation}

Existing methods for bearing voltage prediction are mainly based on equivalent circuits/networks, where the circuit parameters need to be obtained first. The dc resistance is usually calculated from the wire gauge and average turn length. The influence of temperature can also be taken into account by using the conductivities at different operating temperature. FEA has been widely used in estimating machine parameters at the fundamental frequency, such as d-axis and q-axis inductances for PM machines [9].

The measurements of high-frequency winding resistance, inductance and parasitic capacitance are typically performed by impedance analyzers or the equivalent in a wide frequency range. Studies have also been reported on the extraction of electric machine parameters at high frequencies using FEA [10]-[13]. Considering the fact that high-frequency resistances and inductances in electric machines are frequency-dependent, methods are required that can take into account the frequency dependence of parameters.

\section{B. FE Modeling}

This paper proposes to simulate the transient response of bearing voltage in electromagnetic FE transient solver with 


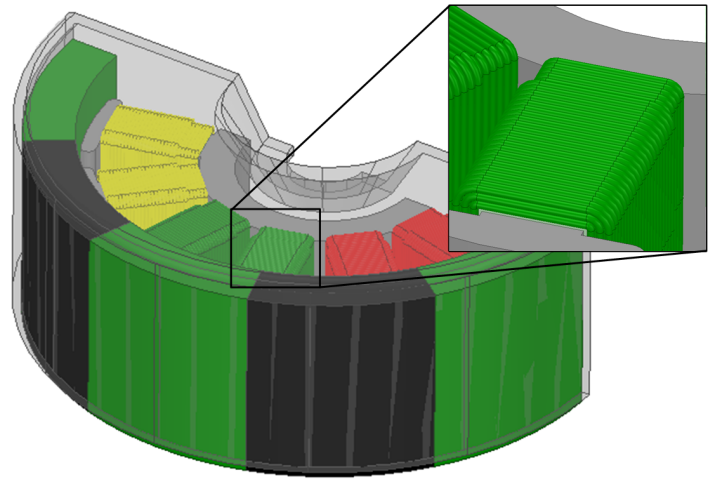

Fig. 5. Detailed solid model for the FE modeling of the motor under study for parameter extraction and transient analysis. Stator windings are modeled turn by turn to capture the distribution effect of parameters.

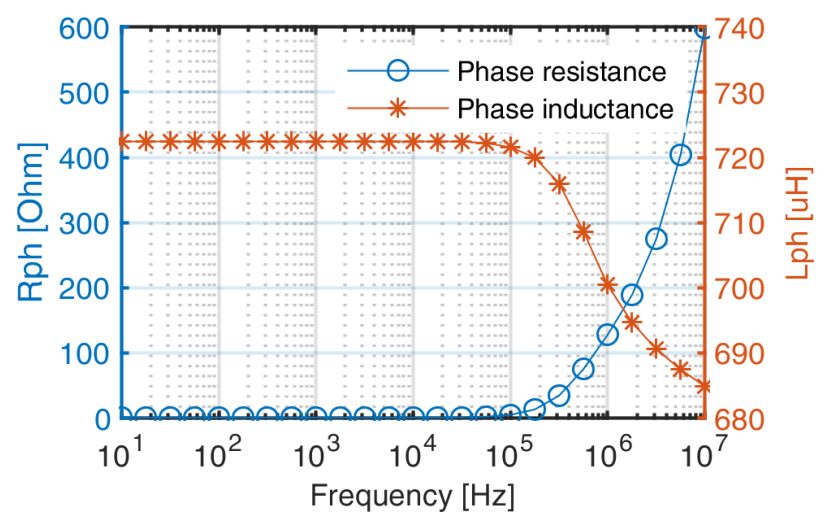

Fig. 6. Phase resistance and inductance vs. frequency from FEA. Eddy currents in conductors are modeled whereas the coreloss effect on the field is not considered.

the help of external circuits. The distributed resistance and inductance are modeled coil by coil. Capacitances need to be extracted first and then incorporated into external circuits. To capture the bearing voltage transients, machine windings need to be modeled in detail to consider the distribution effect of conductors. Each in-slot conductor or turn can be treated as an independent node to consider the voltage distribution along the wire [14].

High-frequency resistances and inductances can be calculated explicitly by an eddy current solver or implicitly by a magnetic transient solver. The FE model with winding details of the PMSM under study is shown in Fig. 5. The calculated phase resistance and inductance are frequency-dependent, as illustrated in Fig. 6. In the range where the frequency is lower than $100 \mathrm{kHz}$, the resistance and inductance are nearly constant. With futher increase in the frequency, the resistance increases drastically and the inductance reduces gradually due to the eddy effect in conductors.

Capacitances in electric machines can be calculated using an electrostatic solver. The 3D mesh for the electrostatic model for the calculation of capacitances shown in Fig. 7 has a total 29.14 million tetrahedrals. The calculated capacitances are independent of the frequency and the voltage distribution is visualized in Fig. 8.

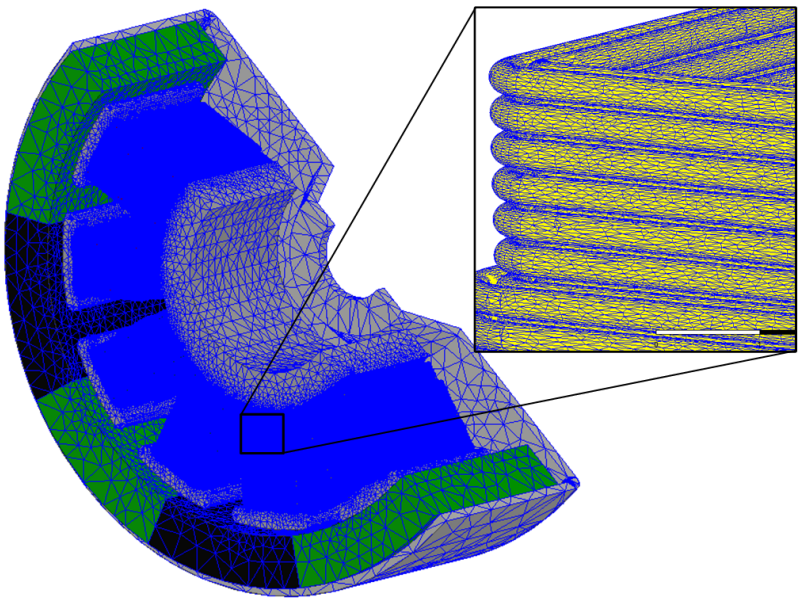

Fig. 7. Meshing of the 3D FE model for an electrostatic solver in ANSYS Maxwell [15]. There are in total 29.14 million tetrahedral elements and it took 35 hours to solve the problem on a high-performance PC with an 8-core Intel Xeon processor and 128GB RAM.

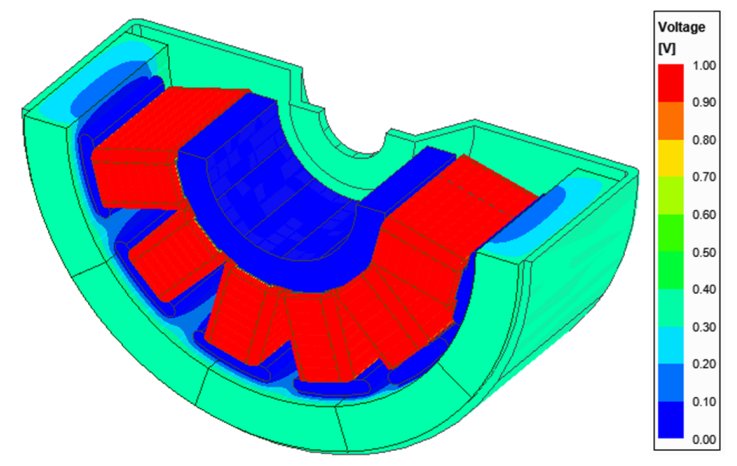

Fig. 8. Voltage distribution within the motor when $1 \mathrm{~V}$ is applied to the stator winding and the stator core is grounded.

In order to show the capacitances in machines with winding details, a 2D FEA model is built with the conductor layout shown in Fig. 9. Coils are assumed to be wound regularly with a needle winder starting from the bottom of the slot. There are 3 conductor layers and the two wires in hand are placed in pairs. The capacitance matrix shown in Fig. 10 has 4 traces highlighted by light colors. The two light blue traces denote capacitances between adjacent conductors from the same layer. The two yellow traces denote capacitances between conductors from adjacent layers. The influence of conductor positions on capacitances can also be observed from results shown in Fig. 11.

For steady-state bearing voltage analysis, all the winding turns are equipotential and the equivalent circuit shown in Fig. 1 can be simplified to a pure capacitve network illustrated in Fig. 12. The constructions of stator and rotor in Fig. 3 show that the laminated stator core and the bearing holder are part of the same assembly and can be treated as a single node. Similarly, the rotor back iron, PM ring and the shaft can be regarded as another node. The winding represents the third node since it is insulated from the stator core and rotor.

The steady-state bearing voltage mirrors the CMV and is 


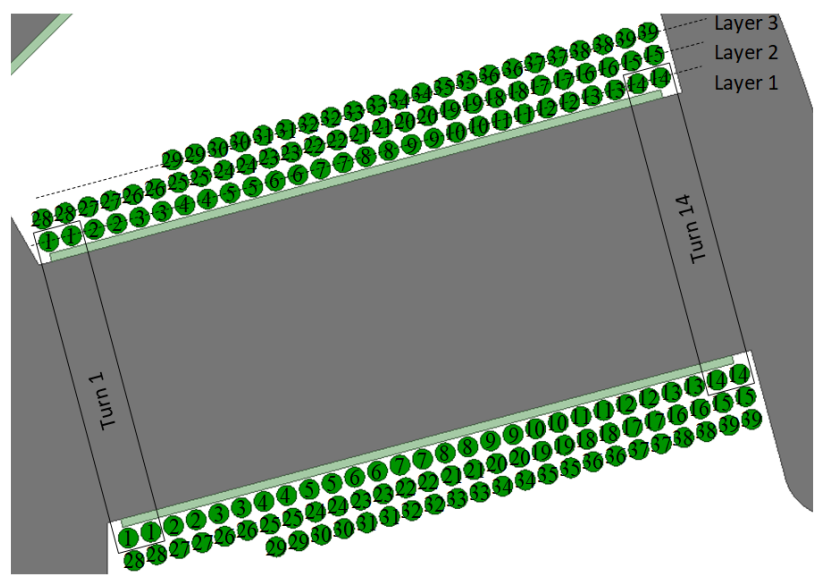

Fig. 9. Layout of turns in one coil of a phase winding. There are two $0.3 \mathrm{~mm}$ wires in hand and coils are assumed to be wound regularly with a needle winder for the simplicity of modeling and analysis.

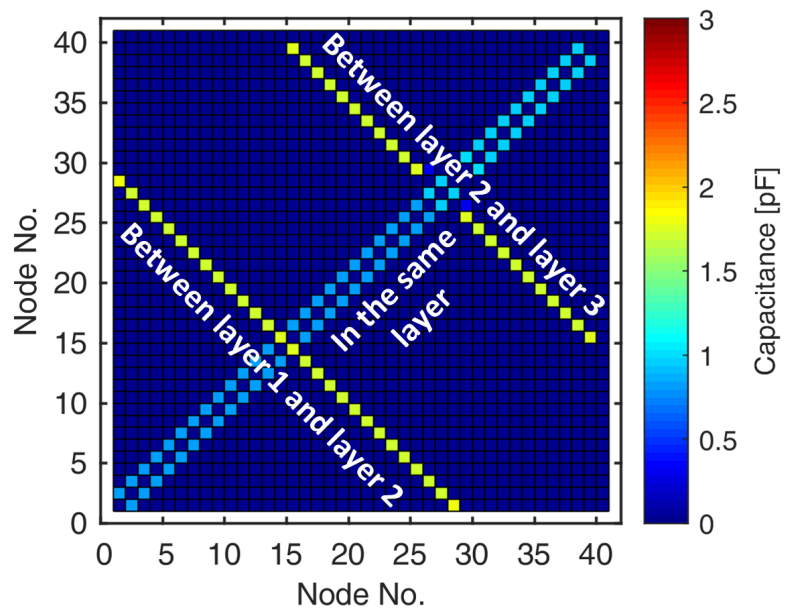

Fig. 10. Capacitance matrix for one coil of Phase B winding from 2D FEA.

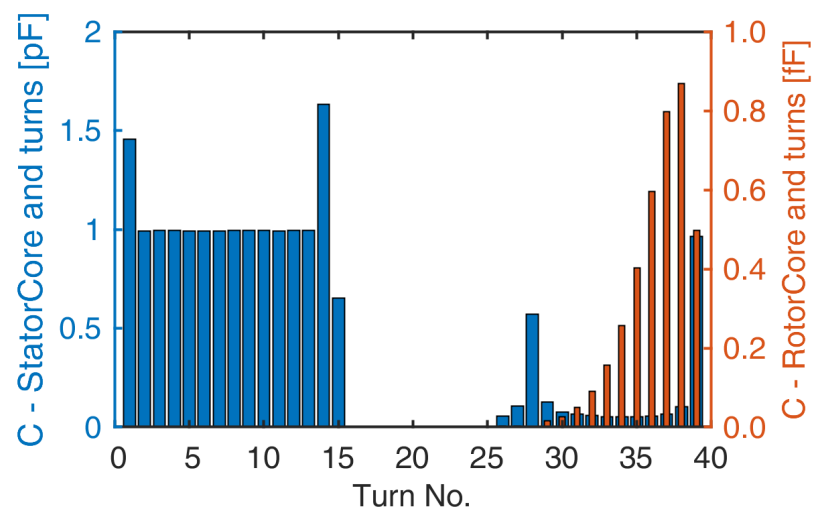

Fig. 11. Winding turn related capacitances from 2D FEA.

determined by the voltage divider, which can be written as:

$$
V_{b}=\frac{C_{w r}}{C_{w r}+C_{s r}+\left(C_{b 1}+C_{b 2}\right)} * C M V
$$

where $C_{w r}$ is the lumped capacitance between stator winding and rotor, $C_{s r}$ the lumped capacitance between stator core and rotor. $C_{b 1}$ and $C_{b 2}$ are the capacitances of bearing 1 and

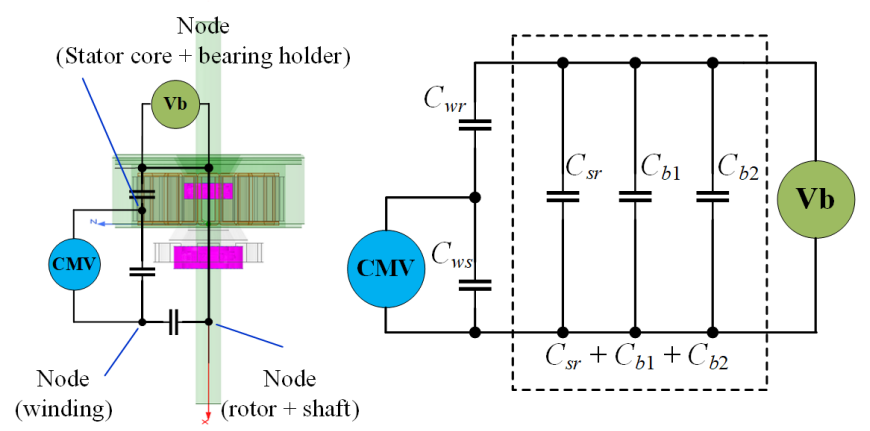

Fig. 12. Equivalent circuit for steady-state analysis.

TABLE I

Comparison of Calculated and Measured Capacitances in the Motor with Full Ceramic Bearings Made of $Z_{r} O_{2}$. The Dielectric Constant of $Z_{r} \mathrm{O}_{2}$ Has a SMall IMPaCt ON THE FE PREDICTED CAPACITANCES.

\begin{tabular}{lcccc}
\hline $\begin{array}{l}\text { Individual } \\
\text { capacitors }\end{array}$ & $\begin{array}{c}\text { FEA } \\
\epsilon_{r}=10[\mathrm{pF}]\end{array}$ & $\begin{array}{c}\text { FEA } \\
\epsilon_{r}=23[\mathrm{pF}]\end{array}$ & $\begin{array}{c}\text { Meas. } \\
{[\mathrm{pF}]}\end{array}$ & $\begin{array}{c}\text { Percentage } \\
\text { Difference [\%] }\end{array}$ \\
\hline$C_{w s}$ & 316.3 & 316.2 & 286.2 & +10.5 \\
$C_{s r}$ & 64.9 & 66.9 & 65.1 & $-0.3 /+2.8$ \\
$C_{w r}$ & 4.5 & 4.5 & 4.0 & +12.5 \\
\hline
\end{tabular}

bearing 2, respectively. It can be seen that the steady-state bearing voltage is independent of the capacitance between stator winding and stator core $C_{w s}$, as well as the capacitances between phase windings $C_{w w}$.

\section{Determination of Bearing Capacitances Based ON A COMBINED NUMERICAL AND EXPERIMENTAL TECHNIQUE}

The winding-to-stator-core capacitance $C_{w s}$, stator-core-torotor-core capacitance $C_{s r}$ and winding-to-rotor-core capacitance $C_{w r}$ are calculated directly from 3D FEA shown in 5 , including the bearings. Full ceramic bearings are used in the FE model to reduce the computation time. The calculated and measured values are tabulated in TABLE I, showing a maximum difference of $12.5 \%$.

The capacitance of a steel ball bearing depends on its construction, lubricant property, lubrication status, operating temperature, speed and load. The dielectric constant of the lubricant mixture $\left(\epsilon_{f}\right)$, lubrication status $\left(\epsilon_{e}\right)$ and additional capacitance $\left(C_{\text {other }}\right)$ introduced by metal ball retainers and seals are difficult to be determined without experimental measurements. To obtain accurate capacitance for steel ball bearings, a combined numerical and experimental approach is developed, which models the steel ball bearing capacitance based on analytical equations according to the Hertzian contact theory and uses measured capacitances to determine the unknown coefficients.

Experimental tests were conducted on the PMSM under study at $1,200 \mathrm{r} / \mathrm{min}$ with a fixed DC bus voltage of $24 \mathrm{~V}$. The space vector PWM (SVPWM) based field-oriented control was employed to control the motor speed with a switching frequency of $20 \mathrm{kHz}$. The CMV and bearing voltage waveforms 


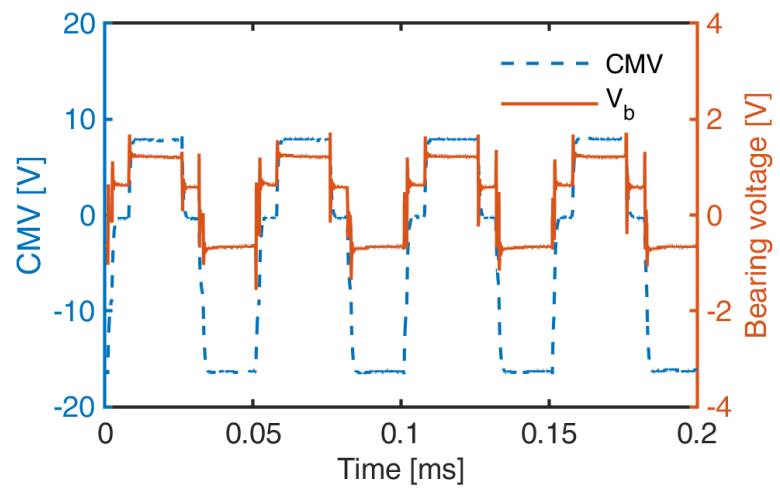

(a)

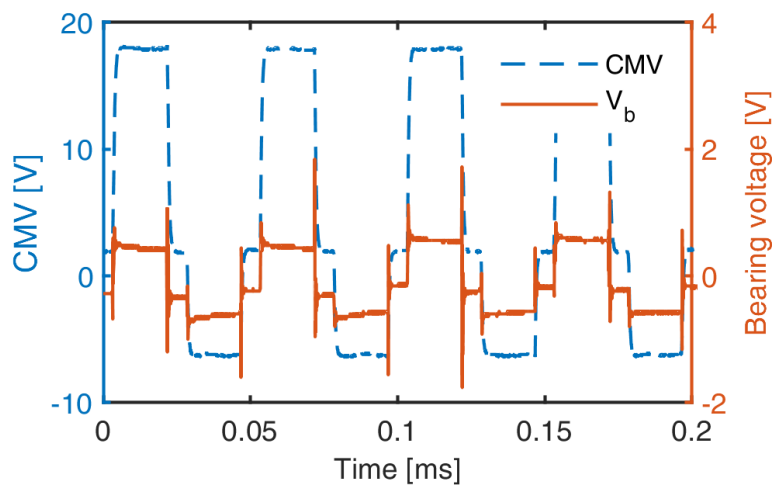

(b)

Fig. 13. Measured common mode voltage and bearing voltage at $1,200 \mathrm{r} / \mathrm{min}$ for: (a) full ceramic bearing, (b) steel ball bearing.

were recorded by an oscilloscope with a sampling frequency of 50MHz, as shown in Fig. 13. The peak-to-peak values of the CMV and bearing voltage were measured from the waveforms and used to calculate the combination $C_{s r}+C_{b 1}+C_{b 2}$, as shown in TABLE II based on the circuit illustrated in Fig. 12.

It can be seen that the bearing voltage mirrors the CMV very well in the tested speed range from $1,200 \mathrm{r} / \mathrm{min}$ to $3,360 \mathrm{r} / \mathrm{min}$. Voltage ringing is observed at the rising and falling edges of the bearing voltage, which might be introduced by the resistances and inductances neglected in the steady-state analysis. The dc bias in the CMV caused by the dc bus voltage pulsation is eliminated in the bearing voltage. The calculated capacitances using analytical equations, FEA and the values calibrated by experimental results are also included in TABLE II, showing satisfactory agreement.

\section{Bearing Voltage Reduction by Insulated SHAFTS AND BEARINGS}

The potential of bearing voltage reduction by insulating the bearing from the shaft and/or bearing holder was studied based on the calibrated equivalent circuit model. The dielectric constant of the E-coating layer and plastic are assumed at the typical value of 3.0.

A layer of insulation was inserted between the inner ring of bearing 608 and shaft or the outer ring of bearing 608 and bearing holder. The influence of the insulation thickness on the voltages of bearing 608 and 688 shown in Fig. 14 indicates that with the increase of the insulation thickness, the voltage of

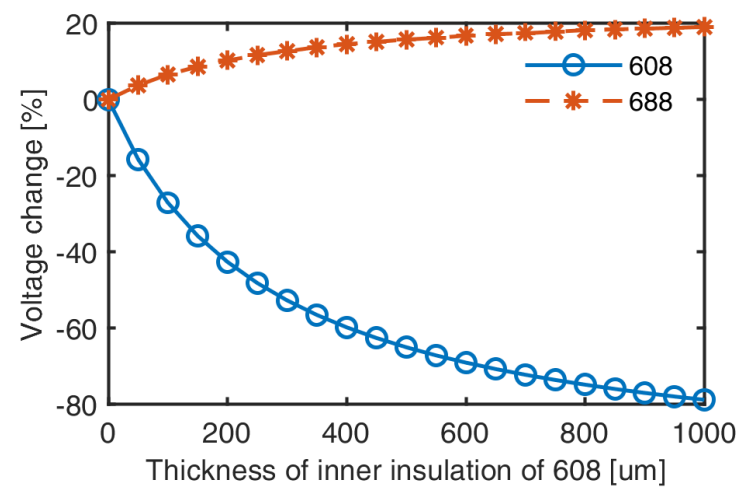

(a)

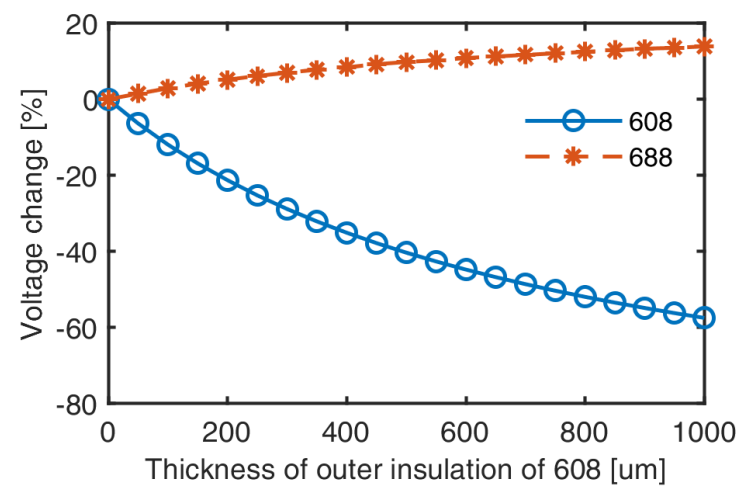

(b)

Fig. 14. Bearing voltage reduction versus the thickness of insulation between: (a) the inner ring of bearing 608 and shaft, (b) the outer ring of bearing 608 and bearing holder. Inner rings have smaller surfaces and therefore produces larger additional impedance and voltage reduction.

the insulated bearing was reduced but the voltage of the noninsulated bearing increased slightly. An $80 \%$ and $55 \%$ voltage reduction can be achieved by insulating the inner ring and outer ring, respectively. Insulating bearing 688 shows similar trends.

Fig. 15 shows that both bearing voltages can be reduced by insulating bearing 608 and bearing 688 at the same time. With a 1-mm thick insulation layer inserted between the inner rings and shaft, the bearing boltages can be reduced by around $70 \%$. In addition, insulating the inner rings reduces more bearing voltage due to the smaller facing surfaces.

\section{CONCLUSION}

This paper studies the bearing voltage reduction potential of using insulated shaft and bearings based on the equivalent circuit representation and FEA. To improve the accuracy of bearing voltage prediction, a model calibration process by combining numerical calculations and experimental measurements is developed.

In order to track the dynamics in bearing voltages when the motor is running, FE models with detailed winding information are required. For steady-state analysis, the simplified equivalent circuit may be used. With the combined numerical and experimental approach, the percentage error for bearing capacitance calculations can be reduced to less than 5\%. Insulating a single bearing can reduce the voltage on the 
TABLE II

Comparison of Calculated and Measured Capacitances. The Regression Analysis Shows that the Optimal CoefFicients are $\epsilon_{f}=$ $5.0, \epsilon_{e}=1.0, C_{o t h e r}=0$. FE-PREDICTED CAPACITANCE $C_{s r}$ IS $61.8 \mathrm{PF}$.

\begin{tabular}{lcccc}
\hline & Full ceramic bearing & \multicolumn{3}{c}{ Steel ball bearing } \\
\hline Speed [r/min] & 1,200 & 1,200 & 2,400 & 3,360 \\
Meas. CMV [V] & 24.0 & 24.0 & 24.2 & 24.4 \\
Meas. $V_{b}[\mathrm{~V}]$ & 1.80 & 1.14 & 1.22 & 1.34 \\
Meas. $C_{s r}+C_{b 1}+C_{b 2}[\mathrm{pF}]$ & 65.1 & 105.15 & 98.0 & 88.85 \\
\hline Calc. $C_{b 1}[\mathrm{pF}]$ & $2.40(\mathrm{FE})$ & 21.2 (anal.) & 16.3 (anal.) & 14.6 (anal.) \\
Calc. $C_{b 2}[\mathrm{pF}]$ & $2.29(\mathrm{FE})$ & 21.5 (anal.) & 16.4 (anal.) & 11.3 (anal.) \\
Calc. $C_{s r}+C_{b 1}+C_{b 2}[\mathrm{pF}]$ & 66.5 & 104.5 & 94.5 & 86.9 \\
\hline Percentage difference $[\%]$ & 2.1 & -0.6 & 3.6 & 2.2 \\
\hline
\end{tabular}

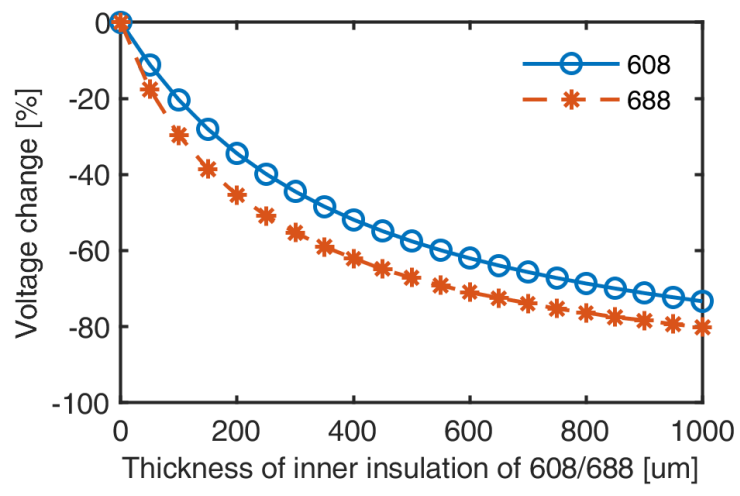

(a)

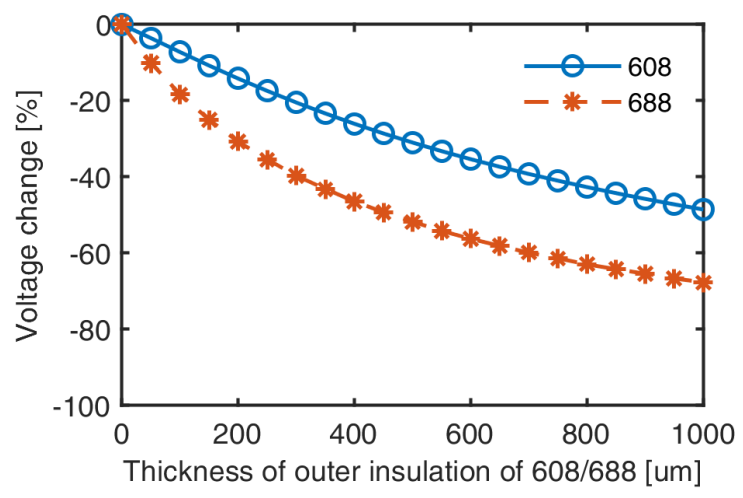

(b)

Fig. 15. bearing voltage reduction versus thickness of insulation layers on: (a) inner surfaces of both bearing 608 and 688, (b) outer surfaces of both bearing 608 and 688 . Voltages of bearing 608 and 688 can be reduced effectively by insulating the inner or outer surfaces of both bearings simultaneously.

insulated bearing but will adversely increase the voltage on the non-insulated bearing. To reduce the voltage of both bearings, it is recommended to insulate the inner rings of both bearings. A maximum voltage reduction of $70 \%$ is predicted in the PMSM under study. Studies for other machine ratings are underway.

\section{ACKNOWLEDGMENT}

The support of Regal Beloit Corporation, University of Kentucky, the L. Stanley Pigman Endowment, and ANSYS Inc., is gratefully acknowledeged.

\section{REFERENCES}

[1] A. Sundaresan and M. Chandorkar, "Traction motor bearing failures due to bearing currents in electric locomotives," in Proc. IEEE Transport. Electrif. Conf. Expo (ITEC), Jun. 2019, pp. 1-6.

[2] J. M. Erdman, R. J. Kerkman, D. W. Schlegel, and G. L. Skibinski, "Effect of PWM inverters on AC motor bearing currents and shaft voltages," IEEE Trans. Ind. Appl., vol. 32, no. 2, pp. 250-259, Mar. 1996.

[3] A. Binder and A. Muetze, "Scaling effects of inverter-induced bearing currents in AC machines," IEEE Trans. Ind. Appl., vol. 44, no. 3, pp. 769-776, May 2008.

[4] T. Plazenet, T. Boileau, C. Caironi, and B. N.-Mobarakeh, "A comprehensive study on shaft voltages and bearing currents in rotating machines," IEEE Trans. Ind. Appl., vol. 54, no. 4, pp. 3749-3759, Jul. 2018.

[5] D. Busse, J. Erdman, R. J. Kerkman, D. Schlegel, and G. Skibinski, "Bearing currents and their relationship to pwm drives," IEEE Trans. Power Electron., vol. 12, no. 2, pp. 243-252, March 1997.

[6] A. Muetze and A. Binder, "Calculation of motor capacitances for prediction of the voltage across the bearings in machines of inverterbased drive systems," IEEE Trans. Ind. Appl., vol. 43, no. 3, pp. 665672, May 2007.

[7] Y. Isomura, K. Yamamoto, S. Morimoto, T. Maetani, A. Watanabe, and K. Nakano, "Study of the further reduction of shaft voltage of brushless dc motor with insulated rotor driven by pwm inverter," IEEE Trans. Ind. Appl., vol. 50, no. 6, pp. 3738-3743, Nov. 2014.

[8] S. Lee, J. Park, C. Jeong, S. Rhyu, and J. Hur, "Shaft-to-frame voltage mitigation method by changing winding-to-rotor parasitic capacitance of ipmsm," IEEE Trans. Ind. Appl., vol. 55, no. 2, pp. 1430-1436, Mar. 2019.

[9] M. Rosu, P. Zhou, D. Lin, D. M. Ionel, M. Popescu, F. Blaabjerg, V. Rallabandi, and D. Staton, Multiphysics Simulation by Design for Electrical Machines, Power Electronics and Drives. Wiley-IEEE Press, 2017.

[10] V. Venegas, J. L. Guardado, E. Melgoza, and M. Hernandez, "A finite element approach for the calculation of electrical machine parameters at high frequencies," in IEEE Power Energy Soc. General Meeting (PESGM), 2007, pp. 1-5.

[11] O. Magdun, S. Blatt, and A. Binder, "Calculation of stator winding parameters to predict the voltage distributions in inverter fed AC machines," in IEEE Int. Symp. Diagnosis for Electric Mach., Power Electron. and Drives (SDEMPED), 2013, pp. 447-453.

[12] V. Mihaila, S. Duchesne, and D. Roger, "A simulation method to predict the turn-to-turn voltage spikes in a PWM fed motor winding," Oct. 2011, pp. 1609-1615.

[13] O. A. Mohammed, S. Ganu, N. Abed, S. Liu, and Z. Liu, "High frequency PM synchronous motor model determined by FE analysis," IEEE Trans. Magn., vol. 42, no. 4, pp. 1291-1294, 2006.

[14] Y. Xie, J. Zhang, F. Leonardi, A. R. Munoz, M. W. Degner, and F. Liang, "Modeling and verification of electrical stress in inverter-driven electric machine windings," IEEE Trans. Ind. Appl., vol. 55, no. 6, pp. 58185829, 2019.

[15] ANSYS Maxwell Capabilities, [Online]. Available: https://www.ansys.com/ products/electronics/ansys-maxwell/maxwellcapabilities. 